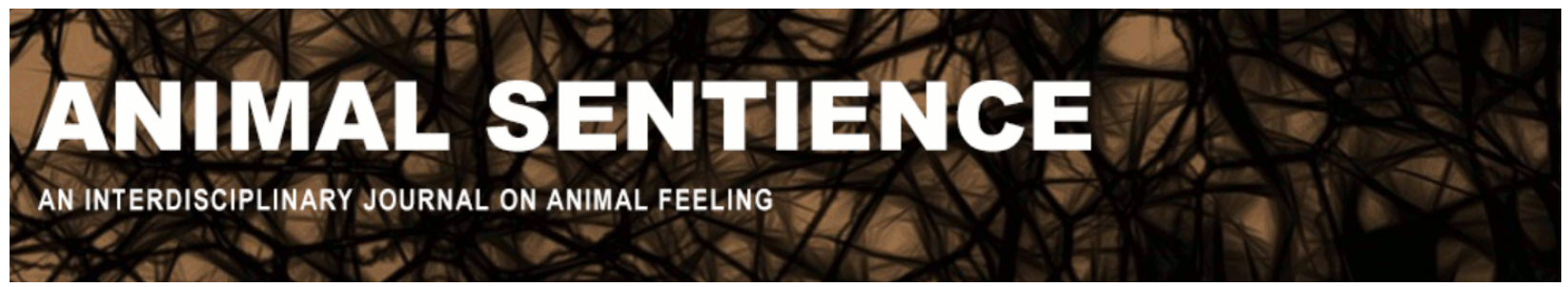

Jürgens, Uta M. (2016) Universal modes of awareness? A "pre-reflective" premise. Animal Sentience 10(6)

DOI: $10.51291 / 2377-7478.1129$

Date of submission: 2016-07-27

Date of acceptance: 2016-08-11

(c)

This article has appeared in the journal Animal

Sentience, a peer-reviewed journal on animal

cognition and feeling. It has been made open access,

free for all, by WellBeing International and deposited

in the WBI Studies Repository. For more information,

please contact

wbisr-info@wellbeingintl.org.

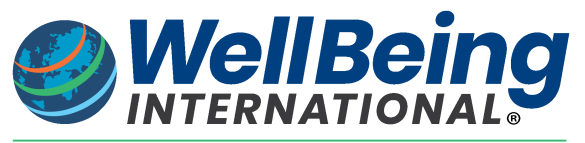

SOLUTIONS FOR PEOPLE, ANIMALS AND ENVIRONMENT 


\title{
Universal modes of awareness? A "pre-reflective" premise
}

Commentary on Rowlands on Animal Personhood

\author{
Uta Maria Jürgens \\ Swiss Federal Institute of Technology Zürich \\ Swiss Federal Research Institute WSL
}

\begin{abstract}
Mark Rowlands holds that creatures endowed with pre-reflective awareness may qualify as persons: In pre-reflective awareness, the self and the unity of mental life are implicit in the stream of experience. Rowlands generalizes from an introspective analysis of pre-reflective consciousness in humans to pre-reflective awareness in general. I describe three examples of empirical findings that corroborate the assumption that animal minds have some of the same basic modes of pre-reflective awareness as human minds.
\end{abstract}

Uta Maria Jürgens is a PhD candidate at the Swiss Federal Institute of Technology in Zürich. Her research is on human-wildlife relations, funded by Deutsche Wildtier Stiftung, while her further interests range from synaesthesia research to anthrozoology and the philosophy of mind. www.uta.info

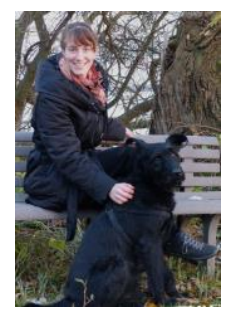

Mark Rowlands (2016) proposes to ground personhood in an intrinsic property of a sentient being's mind: pre-reflective awareness. He explains how in pre-reflective awareness an experiencer's self and the unity of its experiences are a necessary feature of experiencing. Thus a being with pre-reflective awareness qualifies as a Lockean person. Rowlands concludes that personhood extends as far into the animal kingdom as pre-reflective awareness.

I agree with Rowlands's main argument that personhood in non-human beings is based on having pre-reflective awareness. He is right to criticize so-called "higher-order theories" of consciousness that assume a creature can perceive without being aware of its perceptions (Carruthers, 1998). However, I think Rowlands does not do enough to support the claim that non-human beings are pre-reflectively aware of themselves; he seems to take for granted that it is feasible to extrapolate from human awareness to many different species.

Rowlands's idea of the "implicitness" of a self and of mental unity is pivotal for supporting both his general criticism of higher-order theories and his claim that pre-reflective awareness provides everything a creature needs to qualify as a person (as noted in Woodruff's (2016) commentary). I take "implicit" to mean a distinct quality of experience that is neither unconscious nor particularly salient phenomenologically. This implicit self at the gravitational center of experience can be assessed by reflective consciousness. In a Husserlian époché (Husserl, 2012), for example, an introspector endowed with a metacognitive apparatus adopts a distanced explorer's stance toward its stream of experience. It is in such an analytical stance, Rowlands suggests, that the implicit contents of pre-reflective awareness can be made explicit. 
Rowlands's analysis seems to be based on phenomenological introspection and the assumption that pre-reflective awareness is essentially the same for all sentient beings. (Cheng (2016) points to this assumption in his commentary.) This is apparent where Rowlands writes: "A creature that does not have the relevant meta-cognitive abilities, however, is still pre-reflectively aware of itself, for having such awareness is a matter of what would be the case if it were to have such abilities" (Rowlands, 2016, p. 12), or "There is a certain sort of mental life that entails its own unity: to have this sort of mental life at all entails that this mental life is unified" (ibid., p. 15). Rowlands speaks about "mental life" in general here, thus suggesting that pre-reflective awareness, with its implicit self and unity, is shared by all sentient beings - that it is a universal endowment that comes with sentience.

Can we generalize from human pre-reflective experience to animals' experiences - or even to awareness tout court? Are the features of our human awareness shared by all sentient creatures? Rowlands's argument hinges on affirmative answers to these questions.

For Rowlands - as for Husserl (2012) and many others - some qualities or modes (Prentner, 2016) of our experience seem so fundamental that they are assumed without further argument to be universals of awareness: e.g., that a being's experience is situated within a framework of time, space, and mental context such as implicit goals (cf. Brakel, 2016). But that assumption is not trivial. It must be backed by empirical evidence.

While the other-minds problem (Harnad, 2016) requires us to be agnostic as to the exact contents of minds other that our own, I propose that a careful perusal of empirical findings may help support Rowlands's idea that basic modes of experience might be shared among sentient beings.

Harland and Jackson (2004) describe complex predatory behavior in jumping spiders. Spiders of the genus Portia exhibit a highly flexible stalking behavior involving careful spatial navigation relative to a prey which may partly be out of sight. This indicates Portiae's capacity for complex planning towards an implicit goal and for representing the position of its own body in three-dimensional space. Such a representation of self, though rudimentary, may count as an example of an implicit self in Rowlands's sense.

Barron \& Klein (2016) note that for many invertebrates an animal "agent" is the implicit center of its awareness. They discuss behavioral and neuroscientific evidence of the neural correlates of subjective experience and conclude that in all vertebrates and insects "a unified perspective on the world is a key feature of subjective experience" (ibid., p. 4096). This claim has not gone uncriticised (Key, Arlinghaus, \& Browman, 2016), but their proposal is congruent with experimental data as diverse as Harland and Jackson's (2004) contemporary assessments and von Uexküll's (1909) pertinent studies on various invertebrate taxa. These convergent data support the idea that an implicit self and a spatial dimension may be characteristics of subjective states in general.

The temporal dimension of experience is expertly exploited by Western Scrub Jays. In their food caching behavior, these birds show elaborate future planning (Raby, Alexis, Dickinson, \& Clayton, 2007) and episodic memory (Clayton \& Dickinson, 1998). This suggests that jays 
are capable of mentally traveling back and forth in time in order to achieve their (implicit) aims. Even though this capacity may not be as widespread as the implicit self in experience, its existence still suggests that nonhuman animals can cultivate a subjective temporal dimension if selective pressure favors such an evolutionary path.

These pieces of evidence are only preliminary support for Rowlands's pivotal premise. Despite some doubts that unity of non-human mental life can be assumed (Jürgens, 2016), I am confident that empirical findings like these will substantiate the idea that the modes of space and time, as well as the sense of self implicit in pre-reflective awareness will prove to be universal features of awareness in all sentient creatures. I hope Rowlands will review such empirical evidence to strengthen the crucial premise of his otherwise convincing and sound conceptual analysis.

\section{References}

Barron, A. B., \& Klein, C. (2016). What insects can tell us about the origins of consciousness. Proceedings of the National Academy of Sciences, 113(18), 4900-4908.

Brakel, L. A. (2016). Animals are agents. Animal Sentience 2016.103.

Carruthers, P. (1998). Animal subjectivity. Psyche, 4(3), 1-7.

Cheng, K. (1986). A purely geometric module in the rat's spatial representation. Cognition 23(2), 149-178.

Clayton, N. S., \& Dickinson, A. (1998). Episodic-like memory during cache recovery by scrub jays. Nature, 395(6699), 272-274.

Harland, D. P., \& Jackson, R. R. (2004). Portia Perceptions: The Umwelt of an Araneophagic Jumping Spider. In F. R. Prete (Ed.), Complex Worlds from Simpler Nervous Systems (pp. 5-40). Cambridge, MA: MIT Press.

Harnad, S. (2016). Animal Sentience: The other minds problem. Animal Sentience 2016.001.

Husserl, E. (2012). Die Krisis der europäischen Wissenschaften und die transzendentale Phänomenologie. Hamburg: Felix Meiner Verlag.

Jürgens, U. M. (2016). An Animal-Many Persons? Animal Personhood in Face of the Modularity of Mind. International Journal of Social Science Studies, 4(9), 19-26.

Key, B., Arlinghaus, R., \& Browman, H. I. (2016). Insects cannot tell us anything about subjective experience or the origin of consciousness. Proceedings of the National Academy of Sciences, 113(27), E3813-E3813.

Prentner, R. (2016). Erweiteter Geist - Erweitertes Bewusstsein? In J. G. Michel, K. J. Boström, \& M. Pohl (Eds.), Ist der Geist im Kopf? Die These des erweiterten Geistes in Philosophie und Wissenschaft (pp. 109 -131). Münster: mentis.

Raby, C. R., Alexis, D. M., Dickinson, A., \& Clayton, N. S. (2007). Planning for the future by western scrub-jays. Nature, 445(7130), 919-921.

Rowlands, M. (2016). Are animals persons? Animal Sentience 2016.101.

von Uexküll, J. (1909). Umwelt und Innenwelt der Tiere. Berlin: Verlag Julius Springer.

Woodruff, M. L. (2016). Implicit mental processes are an improbable basis for personhood. Animal Sentience 2016.102. 